\title{
REVIEWS.
}

\section{SYNOPSIS OF GYNACOLOGY}

\author{
By H. S. Crossen, M.D. \& Robert James
}

Crossen, M.D. 2nd Edition. Henry

Kimpton, London. 1937. Price 12/6.

This is an excellent little book of 220 pages giving in brief an outline of the salient features of gynæcological practice and is primarily intended for students working for examinations who have not the funds or time to devote to a large text book such as the authors' "Diseases of Women."

This book has over 100 illustrations and is well printed and up-to-date in its pathology and treatment. It can be thoroughly recommended to those for whom it is intended and it will also serve the purpose of a quick referendum to the busy general practitioner.

\section{EMANOTHERAPY.}

By Leonard Williams AND Howard HumpHrIs. Baillière, Tindall \& Cox. London. 1937. Price $7 / 6$.

This book is well written and informative. The subject matter is, however, one which causes a considerable amount of discussion between those who deny the action of those mild radioactive treatments-and there are many of this opinion-and those who claim a most marked action. This book is written by authors who fall into the latter category. However, it behoves practitioners to make themselves familiar with the pros and cons of the argument and this book certainly presents the pros.

\section{ELEMENTS OF ORTHOPFDIC SURGERY.}

By H. Ross Sмiтн. John Wright \& Sons. Bristol. 1937. Price 10/6.

"Elements of Orthopædic Surgery" by H. Ross Smith has been specially devised to give a survey of the whole field of orthopædics suitable for the medical student or general practitioner.

The book is not meant to cover the operative side of orthopædic surgery but it does deal with the great majority of the more common orthopædic conditions in moderate detail.
The author has selected some extremely good illustrations to bring out his different points. We feel that any senior student reading this book would be fairly well conversant with any orthopædic question which might be set in a final examination.

The section on fractures brings in the methods now employed in the treatment of fractures which are commonly in use on the Continent and in this country. The importance of co-operation with the PhysioTherapist is stressed, and some very valuable advice on the fitting of Plaster of Paris casts and the making of plaster beds is included.

Generally speaking, rehabilitation of injured patients has been well emphasised, and we feel that the most surprising thing is the extent of the field covered in what is after all only a very small book.

\section{THE THERAPEUTIC PROBLEM IN BOWEL OBSTRUCTIONS.}

By Owen H. Wangensteen, B.A., M.D. Ph.D. $10 \times 7$, pp. xxii, 360, 90 figs. Baillière, Tindall and Cox. London. 1937. Price 27/-.

This is a notable contribution to the literature of intestinal obstruction. The first section deals with the various pathological problems involved; this is followed by a section devoted to a general consideration of the clinical diagnosis and treatment of obstruction, whilst in the rest of the book the author considers separately the various forms and types of obstruction.

In the first section the factors leading to distension are fully discussed ; the statement is made that " about 68 per cent. of gas in the intestine in obstruction has its origin in swallowed air." Though some experimental work is put forward to support this view we do not think this is sufficiently convincing to permit dogmatism, for certain clinical facts are not compatible with the statement. As regards the cause of death in intestinal obstruction the author concludes that "the chief lethal factor in simple obstruction is 'permeation of a gut wall whose viability has become impaired, by bacteria and other deadly agents '."

Dr. Wangensteen draws attention to the valuable results which have been obtained in the treatment of distension by the use 
of suction applied to an indwelling duodenal tube. Very favourable reports are given of the application of this method to various types of obstruction and to paralytic ileus, and a strong case has been made out for its trial.

We were a little surprised to find the author insisting that obstruction of the large bowel seldom leads to small-gut obstruction. It is true that the ileo-cæcal valve usually remains intact and may even permit the cæcum to dilate enormously and even rupture, but it is also indubitable that occasionally the valve may relax and permit the pressure to work back to the lower smallgut. We have several times seen this happen and are accustomed to teach that the occurrence of vomiting with large-gut obstruction usually indicates that the ileo-cæcal valve has lost its capacity to stop the back-pressure; in such cases a plain X-ray will show both small and large bowel distended.

We were interested in and impressed by the author's plea for the occasional exteriorization of gangrenous or doubtful gut in cases where it would be risky to perform immediate resection. Probably this would lead to the saving of lives. We did not anywhere find mention of the atraumatic type of catgut suture which is such a boon when dealing with thin and damaged intestine.

An excellent series of references is given for every section of the book which we cordially recommend to every surgeon who has to deal with cases of intestinal obstruction.

\section{Forthcoming Medical Books.}

\section{HENRY KIMPTON,}

263, High Holborn, London, W.C.1.

"The Heart in Pregnancy," by Julius Jensen, Ph.D., M.R.C.S., L.R.C.P. In one large octavo volume of 371 pages, with 5 illustrations. Cloth. Price 25/net.

"X-rays and Radium in the Treatment of Diseases of the Skin," by George M. MacKee, M.D. Third Edition, thoroughly revised. In one royal octavo volume of 830 pages, illustrated with 308 engravings, 31 charts, and 2 coloured plates. Cloth. Price 45/- net.

"Management of the Sick Infant and Child," by Langley Porter, B.S., M.D., M.R.C.S. (Eng.), L.R.C.P. (Lond.), and William E. Carter, M.D. Fifth revised edition. In one royal octavo volume of 874 pages, with 94 illustrations. Cloth. Price 42/- net.

"Symptoms of Visceral Disease," by Francis Marion Pottenger, A.M., M.D., LL.D., F.A.C.P. Fifth edition. In one royal octavo volume of 442 pages, with 87 text illustrations and 10 coloured plates. Cloth. Price 24/- net.
"Hemorrhoids," by Marion C. Pruitt, M.D., L.R.C.P.S. (Ed.), F.R.C.S. (Ed.), F.A.C.S. In one large octavo volume of 170 pages, with 73 illustrations, including 7 in colour. Cloth. Price 18/- net.

"Personal Hygiene," by C. E. Turner, M.A., Dr.P.H. In one octavo volume of 335 pages, with 84 text illustrations and 3 coloured plates. Cloth. Price $10 / 6$ net.

"Hernia". Anatomy, Etiology, Symptoms, Diagnosis, Differential Diagnosis, Prognosis, and the Operative and Injection Treatment. By Leigh $F$. Watson, M.D. Second edition. In one large octavo volume of 591 pages, with 28 illustrations. Cloth. Price $31 / 6$ net.

JOHN WRIGHT \& SONS, LTD,

Bristol.

"Synopsis of Physiology," .by Short and Ham.

"Ship Surgeon's Pocket Book," by B. J. Macaulay.

"Anoesthesia \& Analgesia for Nurses and Midwives," by J. K. Watson. 